\title{
Identification of the Dynamic Parameters of the Orthoglide
}

\author{
Sylvain GUEGAN, Wisama KHALIL, Philippe LEMOINE \\ Ecole Centrale de Nantes \\ IRCCyN U.M.R. C.N.R.S. 6597 \\ 1 Rue de la Noë, BP 92101, 44321 Nantes Cedex 03, FRANCE \\ wisama.khalil@irccyn.ec-nantes.fr
}

\begin{abstract}
This paper presents the experimental identification of the dynamic parameters of the Orthoglide [1], a 3-DOF parallel. The dynamic identification model is based on the inverse dynamic model, which is linear in the parameters. The model is computed in a closed form in terms of the Cartesian dynamic model elements of the legs and of the Newton-Euler equation of the platform. The base inertial parameters of the robot, which constitute the identifiable parameters, are given.
\end{abstract}

\section{Introduction}

The inverse dynamic model is important for high performance control algorithms, and the forward dynamic model is required for their simulation. For these two applications the numerical values of the dynamic parameters (inertial and friction) must be known. The determination of the base inertial parameters, which represent the only identifiable parameters [2], is treated in this paper by a numerical method [3]. This method is based on the QR decomposition of the observation matrix of the dynamic identification model of the robot. The experimental identification of the dynamic parameters is based on the use of a dynamic model linear in the parameters. This model permits to use the least squares solution to solve the estimation problem [4].

\section{Kinematic modeling of the Orthoglide}

The Orthoglide has three PRPaR identical legs (where $\mathrm{P}, \quad \mathrm{R}$ and $\mathrm{Pa}$ stand for Prismatic, Revolute and Parallelogram joint, respectively). Each leg is composed of six passive revolute joints and 1 active prismatic joint, (fig. 1). We define frame $F_{0}$ fixed with the base and frame $F_{P}$ fixed with the mobile platform (fig. 2). Their origins are $A_{1}$ and $P$ respectively. Their axes $\left(x_{0}, y_{0}, z_{0}\right)$ and $\left(x_{P}\right.$, $\left.y_{P}, z_{P}\right)$ are parallel. The base frames of the legs are defined by the frames $\mathrm{F}_{\mathrm{A} 1}, \mathrm{~F}_{\mathrm{A} 2}$ and $\mathrm{F}_{\mathrm{A} 3}$ (fig. 2), whose origins are $A_{1}, A_{2}$ and $A_{3}$ respectively. The $\mathrm{z}_{\mathrm{Ai}}$ axes are

This work has been supported by the project MAX of the program ROBEA of the department STIC of the French CNRS. along the prismatic joint axes. The Khalil and Kleinfinger notations [5], are used to describe the geometry of the system (fig. 3).

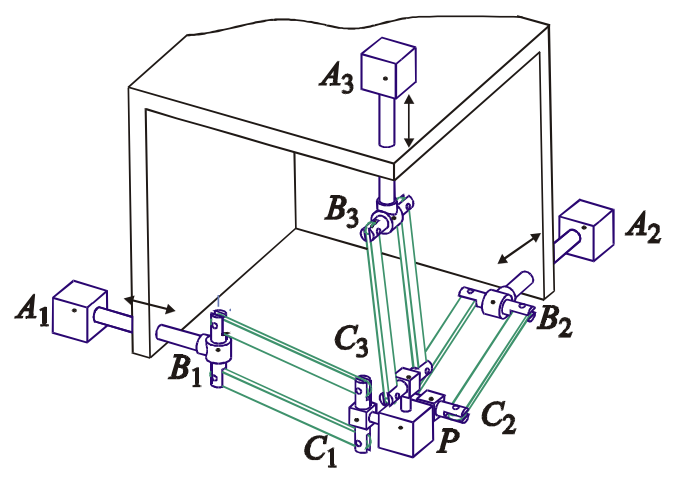

Fig. 1: Orthoglide kinematic architecture.

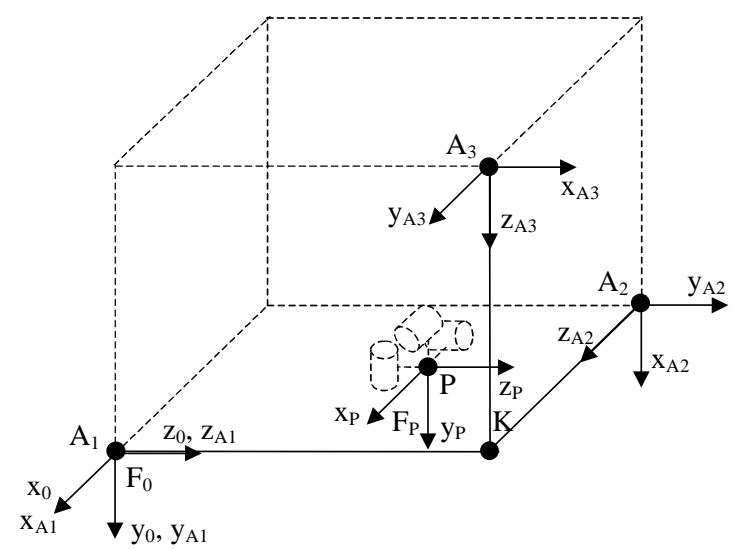

Fig. 2: Base frame, platform frame and leg frames.

The following notations are used:

L $(3 \times 1)$ vector of the motorized joint variables:

$$
\mathbf{L}=\left[\begin{array}{lll}
\mathrm{q}_{11} & \mathrm{q}_{12} & \mathrm{q}_{13}
\end{array}\right]^{\mathrm{T}} ;
$$

${ }^{0} \mathbf{V}_{\mathbf{p}}(3 \times 1)$ vector of the linear velocity of the origin of the platform.

The derivative of $\mathbf{L}$ and ${ }^{0} \mathbf{V}_{\mathbf{p}}$ with respect to the time are denoted $\dot{\mathbf{L}}$ and ${ }^{0} \dot{\mathbf{V}}_{\mathrm{p}}$ respectively. 


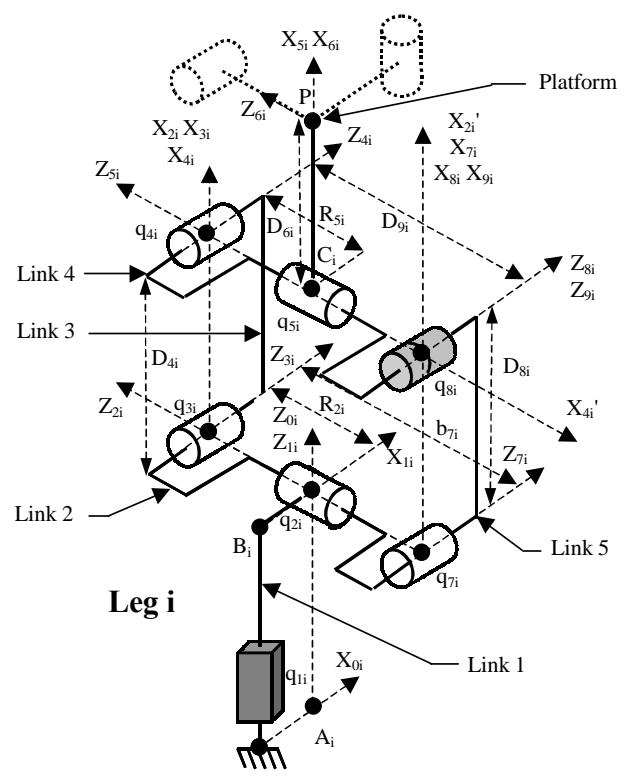

Fig. 3: Link frames of one leg.

The following kinematic models are presented in [6]:

i) The inverse kinematic model of the robot:

$$
\dot{\mathbf{L}}={ }^{0} \mathbf{J}_{\mathbf{p}}^{-10} \mathbf{V}_{\mathbf{p}}
$$

Where ${ }^{0} \mathbf{J}_{\mathbf{P}}^{-1}$ is the inverse Jacobian matrix of the Orthoglide, which is always regular in the working space.

ii) The inverse kinematic model of a leg i:

$$
\begin{aligned}
& \dot{\mathbf{q}}_{\mathbf{i}}={ }^{0} \mathbf{J}_{\mathbf{i}}^{-\mathbf{1}}{ }^{\mathbf{0}} \mathbf{V}_{\mathbf{p}} \\
& \dot{\mathbf{q}}_{\mathbf{i}}=\left[\begin{array}{lll}
\dot{\mathrm{q}}_{1 \mathrm{i}} & \dot{\mathrm{q}}_{2 \mathrm{i}} & \dot{\mathrm{q}}_{3 \mathrm{i}}
\end{array}\right]^{\mathrm{T}}
\end{aligned}
$$

Where ${ }^{0} \mathbf{J}_{\mathbf{i}}^{-1}$ is the inverse Jacobian matrix of the leg i.

The velocities of the other joints of each leg can be obtained in terms of $\dot{\mathbf{q}}_{\mathbf{i}}$ (see appendix).

iii) The second order inverse kinematic model of the leg:

$$
\ddot{\mathbf{q}}_{\mathrm{i}}={ }^{0} \mathbf{J}_{\mathrm{i}}^{-1}\left({ }^{0} \dot{\mathbf{V}}_{\mathrm{p}}-{ }^{0} \dot{J}_{\mathrm{i}} \dot{\mathbf{q}}_{\mathrm{i}}\right)
$$

\section{Inverse dynamic model}

The inverse dynamic model gives the motorized forces, $\Gamma_{\text {robot }}$, in terms of the desired trajectory of the mobile platform ${ }^{0} \mathbf{P}_{\mathbf{p}},{ }^{0} \mathbf{V}_{\mathrm{p}},{ }^{0} \dot{\mathbf{V}}_{\mathbf{p}}$. The dynamic model is computed in two steps. First we calculate, the reaction forces of the platform on the legs at point $\mathrm{P}$, which is denoted by $\mathbf{f}_{\mathbf{i}}$, then the Newton-Euler equation of the platform is applied to obtain the motor forces [6].

The general form of the inverse dynamic model of a leg $\mathrm{i}$, is written as (see appendix):

$$
\Gamma_{\mathrm{i}}=\mathbf{H}_{\mathrm{i}}\left(\mathbf{q}_{\mathrm{i}}, \dot{\mathbf{q}}_{\mathrm{i}}, \ddot{\mathbf{q}}_{\mathrm{i}}\right)+{ }^{0} \mathbf{J}_{\mathrm{i}}^{\mathrm{T}}{ }^{0} \mathbf{f}_{\mathrm{i}}
$$

Where:

$\mathbf{H}_{\mathbf{i}}$ is the inverse dynamic model of leg $\mathrm{i}$, when its terminal point is free.
$\Gamma_{\mathrm{i}}$ is composed of the independent torques/forces of the joints of the leg i, where $\Gamma_{1 \mathrm{i}}$ and $\Gamma_{2 \mathrm{i}}$ are zero:

$$
\Gamma_{\mathrm{i}}=\left[\begin{array}{lll}
\Gamma_{1 \mathrm{i}} & \Gamma_{2 \mathrm{i}} & \Gamma_{3 \mathrm{i}}
\end{array}\right]^{\mathrm{T}}=\left[\begin{array}{lll}
\Gamma_{1 \mathrm{i}} & 0 & 0
\end{array}\right]^{\mathrm{T}}
$$

Using equation (5) the forces $\mathbf{f}_{\mathbf{i}}$ can be written as:

$$
{ }^{0} \mathbf{f}_{\mathrm{i}}=-\mathbf{H}_{\mathrm{xi}}\left(\mathbf{q}_{\mathrm{i}}, \dot{\mathbf{q}}_{\mathrm{i}}, \ddot{\mathbf{q}}_{\mathrm{i}}\right)+{ }^{0} \mathbf{J}_{\mathrm{i}}^{-\mathrm{T}} \Gamma_{\mathrm{i}}
$$

Where:

$$
\mathbf{H}_{\mathrm{xi}}\left(\mathbf{q}_{\mathrm{i}}, \dot{\mathbf{q}}_{\mathrm{i}}, \ddot{\mathbf{q}}_{\mathrm{i}}\right)={ }^{0} \mathbf{J}_{\mathrm{i}}^{-\mathrm{T}} \mathbf{H}_{\mathrm{i}}\left(\mathbf{q}_{\mathrm{i}}, \dot{\mathbf{q}}_{\mathrm{i}}, \ddot{\mathbf{q}}_{\mathrm{i}}\right)
$$

$\mathbf{H}_{\mathbf{x i}}$ is the inverse dynamic model with respect to the position Cartesian space at point $\mathrm{P}$ (fig.3) [7][8]. We show that [6]:

$$
{ }^{\mathbf{0}} \mathbf{f}_{\mathrm{i}}=-\mathbf{H}_{\mathrm{xi}}\left(\mathbf{q}_{\mathrm{i}}, \dot{\mathbf{q}}_{\mathrm{i}}, \ddot{\mathbf{q}}_{\mathrm{i}}\right)+{ }^{0} \mathbf{J}_{\left.\mathbf{p}_{[;: i}^{-\mathrm{T}}\right]}^{\mathrm{T}} \boldsymbol{\Gamma}_{\mathrm{i}}
$$

Where ${ }^{0} \mathbf{J}_{\mathbf{p}[; ;]}^{-\mathbf{T}}$ represents the $i^{\text {th }}$ column of the inverse transpose Jacobian matrix of the robot.

The Newton-Euler equation of the platform is written as (no rotation):

$$
{ }^{0} \mathbf{F}_{\mathbf{P}}={ }^{0} \dot{\mathbf{V}}_{\mathrm{P}} \mathrm{M}_{\mathrm{p}}-\mathrm{M}_{\mathrm{p}}{ }^{0} \mathbf{g}
$$

With:

${ }^{\mathbf{0}} \mathbf{g}$ Acceleration of gravity, referred to frame $\mathrm{F}_{0}$ :

$$
{ }^{\mathbf{0}} \mathbf{g}=\left[\begin{array}{lll}
0 & \mathrm{~g} & 0
\end{array}\right]^{\mathrm{T}}, \mathrm{g}=9.81 \mathrm{~m} \cdot \mathrm{s}^{-2}
$$

$\mathrm{M}_{\mathrm{p}}$ Mass of the platform;

${ }^{0} \mathbf{F}_{\mathbf{p}}$ Total external forces on the platform.

From equations (9) and (10), the dynamic model is given by:

$$
\Gamma_{\text {robot }}={ }^{0} \mathbf{J}_{\mathrm{p}}^{\mathbf{T}}\left({ }^{0} \mathbf{F}_{\mathrm{p}}+\sum_{\mathrm{i}=1}^{3}\left[\mathbf{H}_{\mathrm{xi}}\left(\mathbf{q}_{\mathrm{i}}, \dot{\mathbf{q}}_{\mathrm{i}}, \ddot{\mathbf{q}}_{\mathrm{i}}\right)\right]\right)
$$

Different methods can be used to calculate $\mathbf{H}_{\mathbf{i}}\left(\mathbf{q}_{\mathbf{i}}, \dot{\mathbf{q}}_{\mathbf{i}}, \ddot{\mathbf{q}}_{\mathbf{i}}\right)$ [9][10][11]. To reduce the computational cost, the customized Newton-Euler method, which is linear in the dynamic parameters is used [12].

\section{Dynamic identification model}

The dynamic model of each leg i can be represented as a linear function of the inertial and friction parameters of the leg $\mathbf{K}_{\mathbf{i}}$. Thus the equation (11) can be written as:

$$
\Gamma_{\text {robot }}=\mathbf{D}_{\text {robot }} \mathbf{K}_{\text {robot }}
$$

$\mathbf{K}_{\text {robot }}$ is the vector of the standard dynamic parameters of the Orthoglide:

$$
\begin{aligned}
& \mathbf{K}_{\text {robot }}=\left[\begin{array}{llll}
\mathbf{M}_{\mathrm{P}} & \mathbf{K}_{1}^{\mathrm{T}} & \mathbf{K}_{2}^{\mathrm{T}} & \mathbf{K}_{3}^{\mathrm{T}}
\end{array}\right]^{\mathrm{T}} \\
& \mathbf{D}_{\text {robot }}=\left[\begin{array}{lllll}
\mathbf{D}_{\mathrm{P}} & \mathbf{D}_{\mathbf{1}} & \mathbf{D}_{\mathbf{2}} & \mathbf{D}_{\mathbf{3}}
\end{array}\right]
\end{aligned}
$$

$\mathbf{K}_{\mathbf{i}}$ is the vector of the standard dynamic parameters of the leg i, such that:

$$
\begin{aligned}
& \mathbf{K}_{\mathrm{i}}=\left[\begin{array}{llll}
\mathrm{Ma}_{1 \mathrm{ii}} & \mathrm{Fs}_{1 \mathrm{i}} & \mathrm{Fv}_{1 \mathrm{li}} & \boldsymbol{\chi}_{\mathrm{i}}^{\mathrm{T}}
\end{array}\right]^{\mathrm{T}} \\
& \chi_{\mathbf{i}}=\left[\begin{array}{lll}
\boldsymbol{\chi}_{1 \mathrm{i}}^{\mathrm{T}} & \cdots & \chi_{5 i}^{\mathrm{T}}
\end{array}\right]^{\mathrm{T}}
\end{aligned}
$$

Where: 
- $\mathrm{Ma}_{1 \mathrm{i}}$ is the inertia of the rotor of motor $\mathrm{i}$ referred to the joint side;

- $\mathrm{Fv}_{1 \mathrm{i}}$ is the viscous friction parameter;

- $\mathrm{Fs}_{1 \mathrm{i}}$ is the coulomb friction parameter;

- $\boldsymbol{\chi}_{\mathbf{i}}$ is the vector of the inertial parameters of link $i$.

The standard inertial parameters of the link $\mathrm{j}(\mathrm{j}=1$ to 5 , fig. 3$)$ of the leg $i$ are collected in the $(10 \times 1)$ vector:

$\chi_{\mathrm{ji}}=\left[\mathrm{XX}_{\mathrm{ji}} \mathrm{XY}_{\mathrm{ji}} \mathrm{XZ}_{\mathrm{ji}} \mathrm{YY}_{\mathrm{ji}} \mathrm{YZ}_{\mathrm{ji}} Z_{\mathrm{ji}} \mathrm{MX}_{\mathrm{ji}} \mathrm{MY}_{\mathrm{ji}} \mathrm{MZ}_{\mathrm{ji}} \mathrm{M}_{\mathrm{ji}}\right]^{\mathrm{T}}$

Where:

- $\mathrm{XX}_{\mathrm{ji}}, \ldots, \mathrm{ZZ}_{\mathrm{ji}}$ are the elements of the inertia matrix;

- $\mathrm{MX}_{\mathrm{ji}}, \mathrm{MY}_{\mathrm{ji}}, \mathrm{MZ}_{\mathrm{ji}}$ define the first moments of link ji;

- $\mathrm{M}_{\mathrm{ji}}$ is the mass of link $\mathrm{ji}$.

Thus, $\mathbf{K}_{\text {robot }}$ is a $(160 \times 1)$ vector and $\mathbf{D}_{\text {robot }}$ is a $(3 \times 160)$ matrix.

\subsection{Base dynamic parameters of the robot}

The base dynamic parameters represent the minimum number of parameters from which the dynamic model can be calculated. The dynamic model complexity is reduced when computed by the base dynamic parameters. Besides, they constitute the only identifiable parameters [3]. They can be obtained from the standard parameters, by eliminating the dynamic parameters that have no effect on the dynamic model and by grouping some others.

To determine them, we use a numerical method, which is based on the QR decomposition [4]. First we determine the base parameters of each leg, then we determine the effect of connecting the platform.

There are 14 base parameters for legs 1 and 2. They are given by $(\mathrm{i}=1,2): \mathrm{Ma}_{1 \mathrm{Ri}}, \mathrm{Fv}_{\mathrm{li}_{\mathrm{i}}}, \mathrm{Fs}_{1 \mathrm{i}}, \mathrm{ZZ}_{2 \mathrm{Ri}}, \mathrm{MX}_{2 \mathrm{i}}, \mathrm{MY}_{2 \mathrm{R} \mathrm{i}}$, $\mathrm{XX}_{3 \mathrm{Ri}}, \mathrm{XY}_{3 \mathrm{Ri}}, \mathrm{XZ}_{3 \mathrm{Ri}}, \mathrm{YZ}_{3 \mathrm{Ri}}, \mathrm{ZZ}_{3 \mathrm{Ri}}, \mathrm{MX}_{3 \mathrm{Ri}}, \mathrm{MY}_{3 \mathrm{Ri}}, \mathrm{MX}_{4 \mathrm{i}}$. Since, the prismatic joint of leg 3 is along gravity, there are 15 base parameters for leg 3, the grouped inertia $\mathrm{Ma}_{1 \mathrm{R} 3}$ does not eliminate $\mathrm{M}_{1 \mathrm{R} 3}$ (Whose effect on the force of motor 3 will be constant and equal to $\left.-\mathrm{g} \cdot \mathrm{M}_{1 \mathrm{R} 3}\right)$. The grouped relations are (the index $\mathrm{R}$ indicates that some parameters are grouped with that one):

$$
\begin{aligned}
& \mathrm{Ma}_{1 \mathrm{Ri}}=\mathrm{Ma}_{1 \mathrm{i}}+\mathrm{M}_{1 \mathrm{i}}+\mathrm{M}_{2 \mathrm{i}}+\mathrm{M}_{3 \mathrm{i}}+\mathrm{M}_{4 \mathrm{i}}+\mathrm{M}_{7 \mathrm{i}} \\
& \mathrm{ZZ}_{2 \mathrm{Ri}}=\mathrm{ZZ}_{2 \mathrm{i}}+\mathrm{YY}_{3 \mathrm{i}}+\mathrm{YY}_{4 \mathrm{i}}+\mathrm{D}_{4 \mathrm{i}}^{2} \mathrm{M}_{4 \mathrm{i}}+\mathrm{YY}_{7 \mathrm{i}} \\
& \mathrm{MY}_{2 \mathrm{Ri}}=\mathrm{MY}_{2 \mathrm{i}}+\mathrm{MZ}_{3 \mathrm{i}}+\mathrm{MZ}_{4 \mathrm{i}}+\mathrm{MZ}_{7 \mathrm{i}} \\
& \mathrm{XX}_{3 \mathrm{Ri}}=\mathrm{XX}_{3 \mathrm{i}}-\mathrm{YY}_{3 \mathrm{i}}+\mathrm{XX}_{7 \mathrm{i}}-\mathrm{YY}_{7 \mathrm{i}}-\mathrm{D}_{4 \mathrm{i}}^{2} \mathrm{M}_{4 \mathrm{i}} \\
& \mathrm{XY}_{3 \mathrm{Ri}}=\mathrm{XY}_{3 \mathrm{i}}+\mathrm{XY}_{7 \mathrm{i}} \\
& \mathrm{XZ}_{3 \mathrm{Ri}}=\mathrm{XZ}_{3 \mathrm{i}}-\mathrm{D}_{4 \mathrm{i}} \mathrm{MZ}_{4 \mathrm{i}}+\mathrm{XZ}_{7 \mathrm{i}} \\
& \mathrm{YZ}_{3 \mathrm{Ri}}=\mathrm{YZ}_{3 \mathrm{i}}+\mathrm{YZ}_{7 \mathrm{i}} \\
& \mathrm{ZZ}_{3 \mathrm{Ri}}=\mathrm{ZZ}_{3 \mathrm{i}}+\mathrm{ZZ}_{7 \mathrm{i}}+\mathrm{D}_{4 \mathrm{i}}^{2} \mathrm{M}_{4 \mathrm{i}} \\
& \mathrm{MX}_{3 \mathrm{Ri}}=\mathrm{MX}_{3 \mathrm{i}}+\mathrm{MX}_{7 \mathrm{i}}+\mathrm{D}_{4 \mathrm{i}} \mathrm{M}_{4 \mathrm{i}} \\
& \mathrm{MY}_{3 \mathrm{Ri}}=\mathrm{MY}_{3 \mathrm{i}}+\mathrm{MY}_{7 \mathrm{i}} \\
& \mathrm{M}_{1 \mathrm{R} 3}=\mathrm{M}_{13}+\mathrm{M}_{23}+\mathrm{M}_{33}+\mathrm{M}_{43}+\mathrm{M}_{73}
\end{aligned}
$$

$\mathrm{D}_{4 \mathrm{i}}$ is the distance between the axes of $\mathrm{q}_{3 \mathrm{i}}$ and $\mathrm{q}_{4 \mathrm{i}}$ (fig.3).
Taking into account the three legs and the platform, we obtain that the parameters $\operatorname{MX}_{3 \mathrm{Ri}}(\mathrm{i}=1,2,3)$ are grouped with the mass of the platform and with the parameters: $\mathrm{M}_{1 \mathrm{Ri} 3}, \mathrm{ZZ}_{2 \mathrm{Ri}}, \mathrm{XX}_{3 \mathrm{Ri}}$ and $\mathrm{ZZ}_{3 \mathrm{Ri}}$ :

$$
\begin{aligned}
& \mathrm{M}_{\mathrm{RP}}=\mathrm{M}_{\mathrm{P}}+\frac{1}{\mathrm{D}_{41}} \mathrm{MX}_{3 \mathrm{R} 1}+\frac{1}{\mathrm{D}_{42}} \mathrm{MX}_{3 \mathrm{R} 2}+\frac{1}{\mathrm{D}_{43}} \mathrm{MX}_{3 \mathrm{R} 3} \\
& \mathrm{Ma}_{1 \mathrm{Ri}}=\mathrm{Ma}_{1 \mathrm{Ri}}-\frac{1}{\mathrm{D}_{4 \mathrm{i}}} \mathrm{MX}_{3 \mathrm{Ri}} \\
& \mathrm{ZZ}_{2 \mathrm{Ri}}=\mathrm{ZZ}_{2 \mathrm{Ri}}-\mathrm{D}_{4 \mathrm{i}} \mathrm{MX}_{3 \mathrm{Ri}} \\
& \mathrm{XX}_{3 \mathrm{Ri}}=\mathrm{XX}_{3 \mathrm{Ri}}+\mathrm{D}_{4 \mathrm{i}} \mathrm{MX}_{3 \mathrm{Ri}} \\
& \mathrm{ZZ}_{3 \mathrm{Ri}}=\mathrm{ZZ}_{3 \mathrm{Ri}}-\mathrm{D}_{4 \mathrm{i}} \mathrm{MX}_{3 \mathrm{Ri}} \\
& \mathrm{M}_{1 \mathrm{R} 3}=\mathrm{M}_{1 \mathrm{R} 3}-\frac{1}{\mathrm{D}_{43}} \mathrm{MX}_{3 \mathrm{R} 3}
\end{aligned}
$$

To understand the physical meaning of these grouped parameters, let us consider that the center of mass of links $3_{\mathrm{i}}$ and $7_{\mathrm{i}}$ is in the middle of $\mathrm{O}_{3 \mathrm{i}} \mathrm{O}_{4 \mathrm{i}}$ and $\mathrm{O}_{7 \mathrm{i}} \mathrm{O}_{8 \mathrm{i}}$ respectively.

\begin{tabular}{|c|c|c|c|c|c|c|}
\hline \multicolumn{7}{|l|}{$\bar{~} \mathrm{M}_{\mathrm{RP}}$} \\
\hline $\mathrm{Ma}_{1 \mathrm{Ri}}$ & Off $_{i}$ & $\mathrm{Fv}_{1 \mathrm{i}}$ & $\mathrm{Fs}_{1 \mathrm{i}}$ & $\mathrm{ZZ}_{2 \mathrm{Ri}}$ & $\mathrm{MX}_{2 \mathrm{i}}$ & $\mathrm{MY}_{2 \mathrm{Ri}}$ \\
\hline $\mathrm{XX}_{3 \mathrm{Ri}}$ & $X Y_{3 \mathrm{Ri}}$ & $\mathrm{XZ}_{3 \mathrm{Ri}}$ & $\mathrm{YZ}_{3 \mathrm{Ri}}$ & $Z_{3 \mathrm{Ri}}$ & $\mathrm{MY}_{3 \mathrm{Ri}}$ & $\mathrm{MX}_{4 \mathrm{i}}$ \\
\hline
\end{tabular}
Thus:

$$
\mathrm{MX}_{3 \mathrm{i}}=\frac{\mathrm{D}_{4 \mathrm{i}}}{2} \mathrm{M}_{3 \mathrm{i}}, \mathrm{MX}_{7 \mathrm{i}}=\frac{\mathrm{D}_{4 \mathrm{i}}}{2} \mathrm{M}_{7 \mathrm{i}}
$$

Using equations (18) and (20) into (19), we obtain:

$$
\begin{aligned}
& \mathrm{M}_{\mathrm{RP}}=\mathrm{M}_{\mathrm{P}}+\sum_{\mathrm{i}=1}^{3}\left[\mathrm{M}_{4 \mathrm{i}}+\frac{1}{2} \mathrm{M}_{3 \mathrm{i}}+\frac{1}{2} \mathrm{M}_{7 \mathrm{i}}\right] \\
& \mathrm{Ma}_{1 \mathrm{Ri}}=\mathrm{Ma}_{1 \mathrm{i}}+\mathrm{M}_{1 \mathrm{i}}+\mathrm{M}_{2 \mathrm{i}}+\frac{1}{2} \mathrm{M}_{3 \mathrm{i}}+\frac{1}{2} \mathrm{M}_{7 \mathrm{i}} \\
& \mathrm{M}_{1 \mathrm{R} 3}=\mathrm{M}_{13}+\mathrm{M}_{23}+\frac{1}{2} \mathrm{M}_{33}+\frac{1}{2} \mathrm{M}_{73}
\end{aligned}
$$

From equation (21), we show that:

- The masses $\mathrm{M}_{4 \mathrm{i}}$ are grouped entirely with the platform;

- The masses $M_{3 i}$ and $M_{7 i}$ are divided by two: one half is grouped with the platform and the other with $\mathrm{Ma}_{1 \mathrm{Ri}}$ and also with $\mathrm{M}_{1 \mathrm{R} 3}$ when $\mathrm{i}=3$.

The base dynamic parameters of the Orthoglide are given in table 1 , on which we added an offset on the motor forces. The masse $\mathrm{M}_{1 \mathrm{R} 3}$ will be grouped with $\mathrm{Off}_{3}$. Thus the total number of parameters is 43 .

Table 1: Base inertial parameters of the Orthoglide

So, $\mathbf{K}_{\text {Brob }}$, which contains the base dynamic parameters of the robot, is written as:

$$
\mathbf{K}_{\text {Brob }}=\left[\begin{array}{llll}
\mathbf{M}_{\mathrm{RP}} & \mathbf{K}_{\mathrm{B} 1}^{\mathrm{T}} & \mathbf{K}_{\mathrm{B} \mathbf{2}}^{\mathbf{T}} & \mathbf{K}_{\mathrm{B} \mathbf{3}}^{\mathbf{T}}
\end{array}\right]^{\mathrm{T}}
$$

Where $\mathbf{K}_{\mathbf{B i}}$ is the vector of the base dynamic parameters of the leg i. The corresponding $\mathbf{D}_{\text {Brob }}$ matrix can be written as:

$$
\mathbf{D}_{\text {Brob }}=\left[\begin{array}{llll}
\mathbf{D}_{\mathrm{P}} & \mathbf{D}_{\mathrm{B} 1} & \mathbf{D}_{\mathrm{B} 2} & \mathbf{D}_{\mathrm{B} 3}
\end{array}\right]
$$




\subsection{Computation of $\mathrm{D}_{\mathrm{Brob}}$}

The vector $\mathbf{H}_{\mathbf{i}}$ of the leg i can be written as:

$$
\mathbf{H}_{\mathbf{i}}\left(\mathbf{q}_{\mathrm{i}}, \dot{\mathbf{q}}_{\mathrm{i}}, \ddot{\mathbf{q}}_{\mathrm{i}}\right)=\left[\begin{array}{cc}
\mathbf{D}_{\mathrm{mi}} & \\
0 & \mathbf{D}_{\mathrm{Li}} \\
0 &
\end{array}\right] \mathbf{K}_{\mathrm{Bi}}
$$

Where the elements of $\mathbf{D}_{\mathbf{m i}}$ correspond to the base parameters corresponding to the motorized joint $\left(\mathrm{Ma}_{1 \mathrm{Ri}}\right.$, $\mathrm{Fv}_{1 \mathrm{i}}, \mathrm{Fs}_{1 \mathrm{i}}$ and $\mathrm{Off}_{\mathrm{i}}$ for $\mathrm{i}=1$ to 3 ):

$$
\mathbf{D}_{\mathbf{m i}}=\left[\begin{array}{llll}
\mathrm{D}_{\mathrm{Ma}_{1 \mathrm{Ri}}} & \mathrm{D}_{\mathrm{Fv}_{\mathrm{li}_{\mathrm{i}}}} & \mathrm{D}_{\mathrm{Fs}_{\mathrm{li}_{\mathrm{i}}}} & \mathrm{D}_{\mathrm{Off}_{\mathrm{i}}}
\end{array}\right]
$$

With:

$\mathrm{D}_{\mathrm{Ma}_{1 \mathrm{Ri}}}=\ddot{\mathrm{q}}_{1 \mathrm{i}}, \mathrm{D}_{\mathrm{Fv}_{1 \mathrm{i}}}=\dot{\mathrm{q}}_{1 \mathrm{i}}, \mathrm{D}_{\mathrm{Fs}_{1 \mathrm{i}}}=\operatorname{sign}\left(\dot{\mathrm{q}}_{1 \mathrm{i}}\right)$ and $\mathrm{D}_{\mathrm{Off}_{\mathrm{i}}}=1$.

The columns of $\mathbf{D}_{\mathbf{L i}}$ correspond to the other base parameters.

Then, from (11), and (24), we deduce that:

$$
\begin{aligned}
& D_{\mathrm{P}}={ }^{0} \mathbf{J}_{\mathrm{p}}^{\mathrm{T}}\left({ }^{0} \dot{\mathbf{V}}_{\mathrm{P}}-{ }^{0} \mathbf{g}\right) \\
& \mathbf{D}_{\mathbf{B} 1}=\left[\begin{array}{c:ccc}
\mathbf{D}_{\mathbf{m} 1} & & & \\
0 & { }^{0} \mathbf{J}_{\mathbf{p}}^{\mathbf{T}} & { }^{\mathbf{0}} \mathbf{J}_{1}^{-\mathbf{T}} & \mathbf{D}_{\mathrm{L} 1} \\
0 & & &
\end{array}\right] \\
& \mathbf{D}_{\mathbf{B} 2}=\left[\begin{array}{c:ccc}
0 & & & \\
\mathbf{D}_{\mathbf{m} 2} & { }^{\mathbf{0}} \mathbf{J}_{\mathbf{p}}^{\mathbf{T}} & { }^{\mathbf{0}} \mathbf{J}_{\mathbf{2}}^{\mathbf{T}} & \mathbf{D}_{\mathbf{L} 2} \\
0 & & &
\end{array}\right]
\end{aligned}
$$

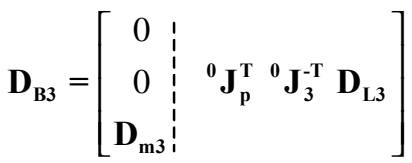

\subsection{Exploitation of the similarity of the legs}

The complexity of the dynamic identification model could be reduced by making use of the similarity of the legs. Thus, the base parameters $\mathrm{ZZ}_{2 \mathrm{Ri}}, \mathrm{MX}_{2 \mathrm{i}}, \mathrm{MY}_{2 \mathrm{Ri}}$, $\mathrm{XX}_{3 \mathrm{Ri}}, \mathrm{XY}_{3 \mathrm{Ri}}, \mathrm{XZ}_{3 \mathrm{Ri}}, \mathrm{YZ}_{3 \mathrm{Ri}}, \mathrm{ZZ}_{3 \mathrm{R} \mathrm{i}}, \mathrm{MY}_{3 \mathrm{Ri}}, \mathrm{MX}_{4 \mathrm{i}}$ of the three legs could be grouped together. Thus the matrix D $_{\text {Brob }}$ becomes:

$$
\begin{gathered}
\mathbf{D}_{\text {sym }}=\left[\begin{array}{c:ccc:c} 
& \mathbf{D}_{\mathrm{m} 1} & 0 & 0 & \\
\mathbf{D}_{\mathbf{P}} & 0 & \mathbf{D}_{\mathrm{m} 2} & 0 & \mathbf{D}_{\mathrm{LS}} \\
& 0 & 0 & \mathbf{D}_{\mathrm{m} 3} &
\end{array}\right] \\
\mathbf{D}_{\mathbf{L S}}={ }^{\mathbf{0}} \mathbf{J}_{\mathbf{p}}^{\mathbf{T}} \sum_{\mathrm{i}=1}^{3}\left[{ }^{\mathbf{0}} \mathbf{J}_{\mathbf{i}}^{\mathbf{T}} \mathbf{D}_{\mathbf{L i}}\right]
\end{gathered}
$$

$\mathbf{K}_{\text {sym }}$ is a $(23 \times 1)$ matrix containing the base inertial parameters of the Orthoglide:

$$
\begin{aligned}
& \mathbf{K}_{\text {sym }}= \\
& {\left[\mathrm{M}_{\mathrm{RP}} \mathrm{Ma}_{1 \mathrm{R} 1} \mathrm{Fv}_{11} \mathrm{Fs}_{11} \mathrm{Off}_{1} \cdots \mathrm{Ma}_{1 \mathrm{R} 3} \mathrm{Fv}_{13} \mathrm{Fs}_{13} \mathrm{Off}_{3} \mathrm{ZZ}_{2 \mathrm{R}} \cdots \mathrm{MX}_{4}\right]^{\mathrm{T}}} \\
& \text { With: } \\
& \mathrm{ZZ}_{2 \mathrm{R}}=\mathrm{ZZ}_{2 \mathrm{R} 1}=\mathrm{ZZ}_{2 \mathrm{R} 2}=\mathrm{ZZ}_{2 \mathrm{R} 3}, \cdots, \mathrm{MX}_{4}=\mathrm{MX}_{41}=\mathrm{MX}_{42}=\mathrm{MX}_{43}
\end{aligned}
$$

\subsection{Identification of the base dynamic parameters}

The identification has been carried out using least squares techniques on the dynamic model as described by Gautier in [13],[14]. To identify the base dynamic parameters some trajectories are sampled at different times. The matrix $\mathbf{D}_{\text {sym }}$ is calculated for each sample and all of them are collected in the matrix $\mathbf{W}$, to obtain the following overdetermined linear system of equations:

$$
\mathbf{Y}=\mathbf{W} \mathbf{K}_{\text {sym }}+\rho
$$

Where:

$\boldsymbol{\rho}$ is the modeling error;

$\mathbf{W}$ is the $(3 \mathrm{r} \times \mathrm{c})$ observation matrix and $\mathbf{Y}$ is the $(3 \mathrm{r} \times 1)$ matrix corresponding to the joint forces for all the samples, with $\mathrm{c}=23$ and $\mathrm{r}$ represents the number of the samples.

The solution of the linear system of equations (32) gives the estimation of the base dynamic parameters.

\section{Experimental results}

The identification method has been experimentally carried out on the Orthoglide prototype of the IRCCyN. The motors are AC servomotors. The control system is based on a DSPACE 1103 digital signal-processing card. The sampling period is $2.5 \mathrm{~ms}$.

\subsection{Planning of the identification trajectory}

To identify the base dynamic parameters the choice of the robot trajectory is very important in order to excite the different parameters [15]. The condition number of $\mathbf{W}$ has been used to select the best trajectory. This number measures the sensitivity of the solution with respect to the noise in the data. The Orthoglide motorized joints could be derived independently. So trajectories have been generated between random joint positions. By simulation we selected 10 random trajectories giving a good condition number. The trajectories are then executed on the real system and sampled with a period which is equal to $2.5 \mathrm{~ms}$. The matrix $\mathbf{D}_{\text {sym }}$ is calculated for each sample and all of them are collected in the observation matrix $\mathbf{W}$.

\subsection{Estimation of the observation matrix}

The computation of the $\mathbf{D}_{\text {sym }}$ matrix needs the estimation of the joint positions, velocities and accelerations. The joint positions are measured thanks to the digital encoder.

The joint positions have been filtered with a $4^{\text {th }}$-order low-pass Butterworth filter in both the forward and reverse directions to avoid phase distortion. The corresponding cut-off frequency is $100 \mathrm{~Hz}$. The joint velocities and accelerations are calculated using numerical derivation based on a central difference 
algorithm. In fact, low-pass filtering associated with a difference algorithm provides a pass-band filter to estimate derivatives at low frequency, which avoid derivating high frequency noise [13].

In order to eliminate high frequency torque noises and ripples from $\mathbf{Y}$, the columns of $\mathbf{W}$ and the vector $\mathbf{Y}$ are filtered in a process called parallel filtering, using the function "decimate" of order 5 from Matlab [13].

\subsection{Estimation of the dynamic parameters}

The least squares solution has been applied to relation (32) in order to estimate the dynamic parameters:

$$
\hat{\mathbf{K}}_{\text {sym }}=\mathbf{W}^{+} \mathbf{Y}
$$

Where $\mathbf{W}^{+}$is the pseudo-inverse of $\mathbf{W}$.

The standard deviations are estimated considering the matrix $\mathbf{W}$ to be deterministic one, and $\boldsymbol{\rho}$ to be a zero mean additive independent noise, with standard deviation $\boldsymbol{\sigma}_{\boldsymbol{\rho}}$. The variance-covariance matrix of the estimation error and standard deviations can be calculated by [13]:

$$
\begin{aligned}
& \mathbf{C}_{\hat{\mathbf{K}}}=\boldsymbol{\sigma}_{\mathbf{\rho}}^{2}\left(\mathbf{W}^{\mathbf{T}} \mathbf{W}\right)^{-1} \\
& \sigma_{\hat{\mathrm{K}} \mathrm{i}}=\sqrt{\mathrm{C}_{\hat{\mathrm{K}} \mathrm{i}}}
\end{aligned}
$$

Where $\boldsymbol{\sigma}_{\mathrm{p}}$ is obtained by the expression:

$$
\hat{\boldsymbol{\sigma}}_{\rho}^{2}=\frac{\|\mathbf{Y}-\mathbf{W} \hat{\mathbf{K}}\|^{2}}{3 r-c}
$$

The relative standard deviation is given by:

$$
\sigma_{\hat{\mathrm{K}} \mathrm{ri}}=100 \frac{\sigma_{\hat{\mathrm{K}} \mathrm{i}}}{\hat{\mathrm{K}}_{\mathrm{i}}}
$$

\begin{tabular}{|c|c|c|c|c|c|}
\hline & $\hat{\mathrm{K}}$ & $\sigma_{\hat{\mathrm{K} r i}}$ & & $\hat{\mathrm{K}}$ & $\sigma_{\hat{\mathrm{K}} \mathrm{ri}}$ \\
\hline $\mathrm{M}_{\mathrm{RP}}$ & 3.2555 & 3.4208 & $O f f_{3}$ & -2.6104 & -23.524 \\
\hline $\mathrm{Ma}_{1 \mathrm{R} 1}$ & 8.9738 & 0.4971 & $\mathrm{ZZ}_{2 \mathrm{R}}$ & -2.8560 & -31.5797 \\
\hline $\mathrm{Fv}_{11}$ & 84.7633 & 0.5559 & $\mathrm{MX}_{2}$ & -4.6706 & -31.0705 \\
\hline $\mathrm{Fs}_{11}$ & 54.35 & 0.4534 & $\mathrm{MY}_{2 \mathrm{R}}$ & -0.0200 & -29.4402 \\
\hline $\mathrm{Ma}_{1 \mathrm{R} 2}$ & 8.843 & 0.4904 & $\mathrm{XX}_{3 \mathrm{R}}$ & 1.5458 & 30.7643 \\
\hline $\mathrm{Fv}_{12}$ & 67.1047 & 0.7118 & $X Y_{3 R}$ & 0.0127 & 23.2455 \\
\hline $\mathrm{FS}_{12}$ & 80.5591 & 0.3105 & $X Z_{3 R}$ & 0.0378 & 14.5685 \\
\hline $\mathrm{Ma}_{13}$ & 8.7612 & 0.5125 & $\mathrm{YZ}_{3 \mathrm{R}}$ & -0.0088 & -22.8285 \\
\hline $\mathrm{Fv}_{13}$ & 83.7167 & 0.5669 & $\mathrm{ZZ}_{3 \mathrm{R}}$ & -0.1356 & -10.103 \\
\hline $\mathrm{Fs}_{13}$ & 54.9855 & 0.4426 & $\mathrm{MY}_{3 \mathrm{R}}$ & 0.0120 & 43.8424 \\
\hline$O f f_{1}$ & -3.0074 & -7.8658 & $\mathrm{MX}_{4 \mathrm{R}}$ & 4.5554 & 31.827 \\
\hline $\mathrm{Off} \mathrm{f}_{2}$ & -1.8386 & -11.989 & & & \\
\hline
\end{tabular}

Table 2 gives the estimated base dynamic parameters and their relative standard deviations:

Table 2: Estimation of the base dynamic parameters

A parameter with $\sigma_{\hat{\mathrm{K} r i}} \geq 15$ is considered to be not good identified [15], it may have a little effect on the model and cannot be identified with acceptable accuracy on the actual trajectory. Taking into account that the parallelograms links are light and symmetric, and considering the grouped relations, we find that $\mathrm{ZZ2} 2_{\mathrm{R}}$, $\mathrm{MX}_{2}, \ldots, \mathrm{MX}_{4}$ are close to zero and can be neglected. Thus, we repeat the identification process with the following essential parameters (table 3):

Table 3: Estimation of the essential base dynamic parameters

\begin{tabular}{|c|c|c|c|c|c|}
\hline & $\hat{\mathrm{K}}$ & $\sigma_{\hat{\mathrm{K}} \mathrm{ri}}$ & & $\hat{\mathrm{K}}$ & $\sigma_{\hat{\mathrm{K}} \mathrm{r}}$ \\
\hline $\mathrm{M}_{\mathrm{RP}}$ & 1.5993 & 1.2601 & $\mathrm{Ma}_{13}$ & 8.6790 & 0.3487 \\
$\mathrm{Ma}_{1 \mathrm{R} 1}$ & 8.7002 & 0.3128 & $\mathrm{Fv}_{13}$ & 83.7047 & 0.5700 \\
$\mathrm{Fv}_{11}$ & 84.6695 & 0.5594 & $\mathrm{Fs}_{13}$ & 54.9723 & 0.4451 \\
$\mathrm{Fs}_{11}$ & 54.4006 & 0.4554 & Off $_{1}$ & -2.5644 & -4.8819 \\
$\mathrm{Ma}_{1 \mathrm{R} 2}$ & 8.4992 & 0.3210 & Off $_{2}$ & -0.4616 & -27.1756 \\
$\mathrm{Fv}_{12}$ & 66.888 & 0.7177 & Off $_{3}$ & -10.1975 & 2.3957 \\
$\mathrm{Fs}$ & 80.7283 & 0.3114 & & & \\
Size of W: 65814 x 13 & \\
Condition number of W: 77.69
\end{tabular}

We note that the identified values are in accordance with respect to our knowledge of the system. The parameters $\mathrm{M}_{\mathrm{RP}}$ is near the a priori value, which is $1.5 \mathrm{Kg}$. The estimation errors of each parameter $\sigma_{\hat{\mathrm{X}} \mathrm{i}}$ are acceptable (except $\mathrm{Off}_{2}$, which could be neglected). The condition number of the observation matrix is very good. We note that the effect of the rotor inertia, viscous friction and coulomb friction of the motorized joints are important compared to the effect of the base parameters of the parallelogram links. The dynamic model corresponding to the parameters of table 3 is easy to compute on line for control purpose.

\subsection{Validation of the results}

Two main validation procedures have been carried out: i) The comparison of the estimated torques with respect to the measured torques on the trajectory that have been used in the identification, and with some other trajectories that have been not used in the identification.

ii) The addition of a payload on the platform to observe the evolution of the mass parameter of the platform $M_{R P}$.

All these tests show very good results.

\section{Conclusion}

This paper presents the identification of the dynamic parameters of the Orthoglide, a 3-DOF parallel robot that moves in the Cartesian space with fixed orientation. The dynamic identification model is based on the inverse dynamic model, which is linear in the parameters. The model is computed in terms of the Cartesian dynamic model elements of the legs and of the Newton-Euler equation of the platform. The base inertial parameters of the robot, which constitute the minimum number of inertial parameters, are determined using a numerical 
method using the QR decomposition. We proposed to make use of the similarity of the legs in order to reduce the number of parameters and to improve the condition number of the observation matrix. Experimental results are presented, and the validation is very good. Future work will concern the use of the identified model to control the robot using a dynamic control law.

\section{References}

[1] Wenger, P., and Chablat D., "Kinematic analysis of a new parallel machine tool : the Orthoglide", Advances in Robot Kinematic, Kluwer Academic Publishers, 2000, pp.305-314.

[2] Mayeda H., Yoshida K., Osuka K., "Base parameters of manipulator dynamic models", IEEE Trans. on Robotics and Automation, Vol. RA-6(3), 1990, pp. 312321.

[3] Gautier, M., "Numerical calculation of the base inertial parameters", IEEE Int. Conf. on Robotics and Automation, Cincinnati, U.S., 1990, pp.1020-1025

[4] Gautier, M., and Khalil, W., "Direct calculation of minimum set of inertial parameters of serial robots", IEEE Trans. on Robotics and Automation, Vol6(3), 1990, pp.368-373.

[5] Khalil, W., and Kleinfinger, J.-F., "A new geometric notation for open and closed-loop robots", Proc. IEEE Conf. on Robotics and Automation, San Francisco, US, 1986, pp.1174-1180.

[6] Guegan, S., and Khalil, W., "Dynamic modeling of the Orthoglide", Advances in Robot Kinematic, Kluwer Academic Publishers, Caldes de Malavella, Spain, 2002, pp.387-396.

[7] Khatib, O., "A unified approach for motion and force control of robot manipulators: the operational space formulation", IEEE J. of Robotics and Automation, Vol. RA-3(1), 1987, pp.43-53.

[8] Lilly, K.W., and Orin D.E., "Efficient $\mathrm{O}(\mathrm{N})$ computation of the operational space inertia matrix", Proc. IEEE Int. Conf. on Robotics and Automation, Cincinnati, US, 1990, pp.1014-1019.

[9] Khalil, W., and Dombre, E., "Modeling, identification and control of robots", Hermes Penton, 2002, London-Paris.

[10] Luh, J.Y.S, Walker, M.W., and Paul, R.C.P., "Online computational scheme for mechanical manipulators", Proc. $2^{\text {nd }}$ IFAC/IFIP Symp. on Information Control Problems in Manufacturing Technology, Stuttgart, 1979, pp.165-172.

[11] Craig J.J., "Introduction to robotics: mechanics and control", Addison Wesley Publishing Company, Reading, 1986.

[12] Khalil, W., and Kleinfinger J.-F., "Minimum operations and minimum parameters of the dynamic model of tree structure robots", IEEE J. of Robotics and Automation, Vol. RA-3(6), 1987, pp.517-526.
[13] Gautier M., "A comparison of filtered models for dynamic identification of robots", Proc. IEEE $35^{\text {th }}$ Conf. on Decision and Control, Kobe, Japon, déc. 1996, pp. 875-880.

[14] Gautier M., Khalil W., Restrepo P.P., "Identification of the dynamic parameters of a closed loop robot", Proc. IEEE Int. Conf. on Robotics and Automation, Nagoya, mai 1995, pp. 3045-3050.

[15]Gautier M., Khalil W., "Exciting trajectories for inertial parameters identification", The Int. J. of Robotics Research, Vol. 11(4), 1992, pp. 362-375.

\section{Appendix : Dynamic model of a leg}

Each leg has a planar parallelogram closed loop. The inverse dynamic model of the equivalent tree structure is obtained by cutting the revolute joint $\mathrm{q}_{8 \mathrm{i}}(\mathrm{i}=1,2,3)$, figure 3:

$$
\Gamma_{\mathrm{tr}_{\mathrm{i}}}=\mathbf{H}_{\mathrm{tr}_{\mathrm{i}}}\left(\mathbf{q}_{\mathrm{i}}, \dot{\mathbf{q}}_{\mathrm{i}}, \ddot{\mathbf{q}}_{\mathrm{i}}\right)
$$

Leg $\mathrm{i}$ is isolated from the platform, so we can consider the variables $\mathrm{q}_{1 \mathrm{i}}, \mathrm{q}_{2 \mathrm{i}}$ and $\mathrm{q}_{3 \mathrm{i}}$ to be independent. In the complete model of the robot, only $\mathrm{q}_{1 \mathrm{i}}$ is active and the torques $\Gamma_{2 \mathrm{i}}$ and $\Gamma_{3 \mathrm{i}}$ are zero.

Let the vector $\mathbf{q}_{\mathbf{a}_{\mathrm{i}}}$ be composed of the independent joints and the vector $\mathbf{q}_{\mathbf{p}_{\mathrm{i}}}$ be composed of the passive joints of leg i:

$$
\mathbf{q}_{\mathbf{a}_{\mathbf{i}}}=\left[\begin{array}{lll}
\mathbf{q}_{1 \mathrm{i}} & \mathrm{q}_{2 \mathrm{i}} & \mathrm{q}_{3 \mathrm{i}}
\end{array}\right]^{\mathrm{T}} \quad \mathbf{q}_{\mathbf{p}_{\mathbf{i}}}=\left[\begin{array}{lll}
\mathrm{q}_{4 \mathrm{i}} & \mathrm{q}_{5 \mathrm{i}} & \mathrm{q}_{7 \mathrm{i}}
\end{array}\right]^{\mathrm{T}}
$$

The constraint equations of the loop are:

$$
\mathrm{q}_{4 \mathrm{i}}=-\mathrm{q}_{3 \mathrm{i}}, \quad \mathrm{q}_{5 \mathrm{i}}=-\mathrm{q}_{2 \mathrm{i}}-\frac{\pi}{2}, \quad \mathrm{q}_{7 \mathrm{i}}=\mathrm{q}_{3 \mathrm{i}}, \quad \mathrm{q}_{8 \mathrm{i}}=-\mathrm{q}_{3 \mathrm{i}}
$$

The dynamic model of the leg is obtained from $\Gamma_{t_{i}}$ and the constraint equations by [9]:

$$
\begin{aligned}
& \Gamma_{\mathbf{i}}=\mathbf{H}_{\mathbf{i}}\left(\mathbf{q}_{\mathbf{i}}, \dot{\mathbf{q}}_{\mathrm{i}}, \ddot{\mathbf{q}}_{\mathrm{i}}\right) \\
& \Gamma_{\mathrm{i}}=\left[\begin{array}{lll}
\Gamma_{1 \mathrm{i}} & \Gamma_{2 \mathrm{i}} & \Gamma_{3 \mathrm{i}}
\end{array}\right]^{\mathrm{T}}=\mathbf{G}_{\mathbf{i}}{ }^{\mathrm{T}} \Gamma_{\mathrm{tr}_{\mathrm{i}}}
\end{aligned}
$$

With: $\mathbf{G}_{\mathbf{i}}=\frac{\partial \mathbf{q}_{\mathbf{t r}_{\mathrm{i}}}}{\partial \mathbf{q}_{\mathrm{a}_{\mathrm{i}}}}$ and $\mathbf{q}_{\mathrm{tri}_{\mathrm{i}}}=\left[\begin{array}{ll}\mathbf{q}_{\mathrm{a}_{\mathrm{i}}}^{\mathrm{T}} & \mathbf{q}_{\mathbf{p}_{\mathrm{i}}}^{\mathrm{T}}\end{array}\right]^{\mathrm{T}}$, thus:

$$
\mathbf{G}_{\mathbf{i}}{ }^{\mathbf{T}}=\left[\begin{array}{cccccc}
1 & 0 & 0 & 0 & 0 & 0 \\
0 & 1 & 0 & 0 & -1 & 0 \\
0 & 0 & 1 & -1 & 0 & 1
\end{array}\right]
$$

The dynamic model of the tree structure is obtained by recursive symbolic Newton-Euler method [12].

Since all the parameters of the $5^{\text {th }}$ and $7^{\text {th }}$ links are grouped with the other links. Thus the matrix $\mathbf{G}$ can be reduced to the first 4 columns:

$$
\mathbf{G}_{\mathbf{i}}{ }^{\mathrm{T}}=\left[\begin{array}{cccc}
1 & 0 & 0 & 0 \\
0 & 1 & 0 & 0 \\
0 & 0 & 1 & -1
\end{array}\right]
$$

And:

$$
\Gamma_{\mathrm{tr}_{\mathrm{i}}}=\left[\begin{array}{lll}
\Gamma_{\mathrm{tr}_{\mathrm{ii}}} & \cdots & \Gamma_{\mathrm{tr}_{\mathrm{ti}}}
\end{array}\right]^{\mathrm{T}}
$$

